\title{
BMJ Open Impact of smoking on the income level of Chinese urban residents: a two-wave follow-up of the China Family Panel Study
}

\author{
Han Wei (D) , ${ }^{1}$ Zhigang Zhong, ${ }^{1}$ Lian Yang, ${ }^{2}$ Tingting Yao, ${ }^{3}$ Shiyao Huang, ${ }^{1}$ \\ Zhengzhong $\mathrm{Mao}^{4}$
}

To cite: Wei H, Zhong Z, Yang L, et al. Impact of smoking on the income level of Chinese urban residents: a two-wave follow-up of the China Family Panel Study. BMJ Open 2020;10:e036939. doi:10.1136/ bmjopen-2020-036939

- Prepublication history for this paper is available online. To view these files, please visit the journal online (http://dx.doi. org/10.1136/bmjopen-2020036939).

HW and ZZ contributed equally.

HW and ZZ are joint first authors.

Received 14 January 2020 Revised 04 July 2020 Accepted 07 July 2020
Check for updates

(C) Author(s) (or their employer(s)) 2020. Re-use permitted under CC BY-NC. No commercial re-use. See rights and permissions. Published by BMJ.

For numbered affiliations see end of article.

Correspondence to

Dr Lian Yang;

yyanglian@163.com

\section{ABSTRACT}

Objectives This study attempts to analyse the impact of smoking on the income level of Chinese urban residents to provide a reference for creating informed regulations on cigarette smoking.

Design A population-based cohort study.

Method Two waves of panel data in 2014 and 2016 from the China Family Panel Study were used. A total of 8025 urban adults were identified. The Hausman-Taylor model was used to analyse the theoretical relationship between smoking and income.

Results The percentage of current smokers decreased from $27.39 \%$ (2014) to $26.24 \%$ (2016), while the percentage of former smokers rose from $9.78 \%$ to $11.78 \%$. The results from the Hausman-Taylor model showed that current smokers and former smokers are associated with statistically significant decrease in the income of urban residents of $37.70 \%$ and $44.00 \%$, respectively, compared with that of non-smokers. After eliminating the impact of smoking on income, the poverty rate among urban residents decreased from $15.33 \%$ to $13.63 \%$.

Conclusions Smoking can significantly reduce the income of Chinese urban residents, resulting in immense negative impacts on Chinese society. Therefore, the government should raise the tax rate on tobacco, include smoking cessation treatment in medical insurance coverage, promote publicity campaigns on the awareness of tobacco hazards and encourage smokers to quit smoking early.

\section{INTRODUCTION}

China is the world's largest cigarette producer, manufacturer and consumer. As shown in the 2018 Global Adult Tobacco Survey data, the current smoking prevalence of Chinese people aged 15 and above is $26.6 \%$, and the population of smokers has reached 308 million. ${ }^{1}$ Diseases caused by smoking, such as cardiovascular diseases, cancer and chronic respiratory diseases, have become China's major health threats. ${ }^{2-5}$ From 1990 to 2010, the number of deaths caused by smoking increased from 700000 to
Strengths and limitations of this study

- This study supplements the empirical research conclusions on the relationship between smoking and resident income in China.

- Two-wave balance panel data can improve the effectiveness of model estimation and the estimation accuracy.

- The Hausman-Taylor model can also overcome the endogeneity problems with the instrumental variables automatically generated from internal information in the model.

- This study was limited to urban residents without consideration of the impact of smoking on the income of other populations.

1.4 million. ${ }^{6}$ Smoking-attributable deaths per year in China are predicted to reach 3 million by 2050 if the problem remains unchecked. ${ }^{7}$

It is well known that smoking negatively impacts people's health. Recently, an increasing number of scholars have been paying attention to the impact of smoking on personal income level. ${ }^{8-12}$ Most research shows that smoking negatively affects income. Böckerman et al noted the long-term negative impact of smoking on the income of Finnish males. ${ }^{8}$ Auld concluded that Canadian smokers' income was $8 \%$ lower than the nonsmokers' income, and the smoking penalty rose to $24 \%$ after correcting for endogeneity. ${ }^{9}$ Dutch smokers are paid approximately $10 \%$ less than non-smokers according to van Ours's research results. ${ }^{10}$ Lokshin and Beegle used data from the 2005 Albanian Living Standards Surveillance Survey and discovered that smokers earn $20 \%$ less than non-smokers. ${ }^{11}$ In addition, a few studies have also shown less significant relationship between smoking and individual income. Lye and Hirschberg used 1995 Australian National Health Survey data 
to suggest that cigarette smoking did not significantly impact personal income. ${ }^{12}$

Previous studies have shown that three major reasons cause smoking to reduce income. First, smoking reduces the productivity of smokers. Kristein believes that smokers have more absent time and relatively lower productivity caused by smoking breaks or sick leave due to poor health. ${ }^{13}$ Second, smokers have a relatively higher time preference, which means that they prefer current consumption to investment for the future. This preference may result in lower human capital investment in themselves, which in turn leads to lower income. ${ }^{14}$ Third, smokers are personally less attractive than non-smokers. Smoking affects an individual's personal appearance and smell and, thus, reduces his or her personal attractiveness. ${ }^{15}$

There is a limited amount of related studies in China. Yin and Gan concluded that smoking does not significantly affect resident income using data from the 1991-2006 China Health and Nutrition Survey. ${ }^{16}$ The methodology adopted in this research involved a pooled regression model; however, this approach has limitations. The usage of panel data as the pooled data ignores the individual effects of research objects, which yields a research result that may not be robust. This study explores the possible impact of smoking on Chinese residents' income, with the aim to contribute to the methodologies used in previous Chinese studies, to accurately estimate the economic losses caused by smoking and to provide useful evidence for tobacco intervention policymaking decisions.

\section{DATA AND MODEL Data resources}

The data in this study were derived from the China Family Panel Studies (CFPS) operated by the China Social Science Research Center of Beijing University. ${ }^{17}$ CFPS is a national, large-scale, multidisciplinary social tracking survey project conducted every 2years starting from 2010. CFPS adopted an implicit stratification strategy involving a multiphase and multilevel probability sampling method proportional to size, covering 25 provinces/municipalities/autonomous regions in the country (unsampled provinces/municipalities/autonomous regions include Hong Kong, Macau, Taiwan, Xinjiang, Tibet, Qinghai, Inner Mongolia, Ningxia and Hainan). Based on the regional distribution of sampling and the sampling method, this database is well representative and rigorous.

Face-to-face computer-assisted personal interviews involving demographic background, smoking habits, health status and personal income were conducted to ensure the objectivity and logicality of the data. This study used two waves of data that were publicly released by the CFPS. Since the CFPS questionnaire included rural residents' agricultural income in the household income data and it is difficult to accurately define the personal income of rural residents, the research subjects were limited to urban residents.

\section{Patient and public involvement}

All data in this study were derived from the CFPS database, and no patient and the public were involved in the design or planning of this study.

\section{Study sample}

CFPS surveyed 10874 and 9942 urban individuals in 2014 and 2016, respectively, and $73.80 \%$ of individuals were successfully followed in the two waves. We eventually included 4428 households and 8025 respondents and constructed balanced panel data.

\section{Measures}

\section{Smoking variables}

Respondents were divided into groups of non-smokers, current smokers and former smokers. The CFPS questionnaire asked, 'Have you smoked in the last month?' When the respondent answered 'yes', the individual was categorised as a 'current smoker'; if the respondent answered 'no', he or she was then asked, 'Have you ever smoked?' If the respondent answered 'yes', the individual was considered to be a 'former smoker'; if the answers to both questions were 'no', the respondent was considered a non-smoker.

\section{Control variables}

Demographic characteristics included gender (woman or man), age ( $<35$ years old, 35 - yearsold, $\geq 60$ years old), education (primary school and below, middle school and high school or junior college and above), marital status (in a marriage, married/cohabiting or not in a marriage, single or separated/divorced/widowed), self-rated health status (poor, average or healthy), chronic disease status (yes or no), health insurance status (yes or no), alcohol intake (yes or no), doing physical exercise or not (yes or no), type of employment (unemployed, manager, professional and technical personnel, clerks and related personnel, service personnel, workers in agricultural, forestry, animal husbandry, fishing and water conservancy sectors, production workers and transportation equipment operators and related personnel, others), gross domestic product (GDP) per capita and the survey year (2014 or 2016).

\section{Dependent variable}

The dependent variable in this study was the income of urban residents. The income variable was the total annual income of the respondents, including annual wages, overtime wages and bonuses, year-end bonuses, physical conversions received, income from a second occupation, retirement pensions and net income from personal businesses. To eliminate the impact of price factors on income in different years, the consumer price index was used to correct the nominal value of income in 2016 which was converted to personal income measured at constant prices in 2014.

\section{Poverty rate}

The poverty line criterion used was the 2010 poverty line standard of 2300 yuan per year. The nominal value was corrected with the consumer price index and transformed based on the poverty line measured by the constant price 
of 2014. Measuring the extent of poverty, poverty rate represents the percentage of people below the poverty line in the total population.

\section{Statistical analysis}

In the study of the effects of smoking on income, data endogeneity is unavoidable. There are two causes for this endogeneity. One cause may be omitted variables that have an impact on outcome. For example, people with less self-control are more likely to develop a smoking habit. Self-control is an omitted variable that is rarely observed in research. Another possibility is that income level might affect smoking behaviours. ${ }^{16}$ Smoking is addictive, and smoking behaviours are difficult to change. Analysing them with the select panel data fixed-effect model will result in a loss of samples with unchanged smoking status and, thus, fitting model parameters that deviate from reality. ${ }^{18}$ To ensure the robustness of the analysis results, this study used the Hausman-Taylor model. The basic principle of the Hausman-Taylor model is to solve the endogeneity problems with the instrumental variables automatically generated from internal information in the model. In addition, the model can include variables that do not change over time and, thus, reduce sample loss. ${ }^{19}$

The basic econometric model of smoking impact on income was structured on Mincer's income equation by introducing smoking status variables into independent variables, ${ }^{20}$ which were finally modified to obtain the Hausman-Taylor model.

$$
\operatorname{Ln}\left(\text { Income }_{i t}\right)=\beta_{0}+\beta_{1} \text { Smoking }_{i t}+\beta_{2} \mathrm{X}_{\mathrm{it}}+\eta \mathrm{Z}_{\mathrm{i}}+\mathrm{a}_{\mathrm{i}}+\mathrm{u}_{\mathrm{it}}
$$

In the formula, $\operatorname{Ln}\left(\right.$ Income $\left._{\mathrm{it}}\right)$ represents the logarithm of the annual income of individual $\mathrm{i}$ in $\mathrm{t}$ years; Smoking $_{\text {it }}$ is a dummy variable of the smoking status of the respondents; $\mathrm{X}_{\mathrm{it}}$ is a control variable that changes over time which includes age, education level, marital status, self-rated health status, chronic disease status, medical insurance status, alcohol consumption status, employment status, location and survey year; $\mathrm{Z}_{\mathrm{i}}$ is a control variable that remains unchanged over time which includes gender; $a_{i}$ indicates the differences between individuals and remains unchanged over time and $\mathrm{u}_{\mathrm{it}}$ is the error term. A semilogarithmic equation means that a change in the independent variable causes a percentage change in the dependent variable when other variables remain constant.

This study describes the sociodemographic characteristics (gender, age, education levels, marital status, etc.), health behaviours (including smoking status, alcohol intake and doing physical exercise or not), health status (self-rated health status and having chronic disease or not), health insurance status, type of employment, per capita GDP and income of Chinese urban residents in years 2014 and 2016 (see table 1). Moreover, this study describes the smoking status among different characteristics groups (eg, gender and age) of Chinese urban residents in 2014 and 2016 (see table 2). In addition, it analyses income distribution of urban resident in different
Table 1 Characteristics of urban resident in 2014 and 2016, China

\begin{tabular}{|c|c|c|}
\hline Variables & $2014(n=8025)$ & $2016(n=8025)$ \\
\hline \multicolumn{3}{|l|}{ Smoking status, $\mathrm{N}(\%)$} \\
\hline Non-smokers & $5042(62.83)$ & 4974 (61.98) \\
\hline Current smokers & 2198 (27.39) & $2106(26.24)$ \\
\hline Former smokers & $785(9.78)$ & $945(11.78)$ \\
\hline Annual income (US\$) (mean \pm SD) & $2761.93 \pm 4927.22$ & $4807.02 \pm 9163.16$ \\
\hline GDP per capita (US\$) (mean \pm SD) & $8806.48 \pm 3535.47$ & $9370.96 \pm 4215.79$ \\
\hline \multicolumn{3}{|l|}{ Gender, n (\%) } \\
\hline Male & $4245(52.90)$ & $4245(52.90)$ \\
\hline Female & $3779(47.10)$ & $3779(47.10)$ \\
\hline \multicolumn{3}{|l|}{ Age, n (\%) } \\
\hline$<35$ & $1288(16.05)$ & $1035(12.90)$ \\
\hline $35-$ & $4439(55.31)$ & $4322(53.86)$ \\
\hline$\geq 60$ & $2298(28.64)$ & $2668(33.25)$ \\
\hline \multicolumn{3}{|l|}{ Marital status, n (\%) } \\
\hline Married & $6974(86.92)$ & $6977(86.94)$ \\
\hline Not in marriage & $1050(13.08)$ & $1048(13.06)$ \\
\hline \multicolumn{3}{|l|}{ Education level, $\mathrm{n}(\%)$} \\
\hline Primary school and below & $2866(35.71)$ & $2866(35.71)$ \\
\hline Middle school and high school & $4120(51.34)$ & $4110(51.21)$ \\
\hline Junior college and above & $1039(12.95)$ & $1049(13.07)$ \\
\hline \multicolumn{3}{|l|}{ Self-rated health status, $n(\%)$} \\
\hline Poor & $1143(14.24)$ & $1193(14.87)$ \\
\hline Average & $1351(16.83)$ & $1788(22.28)$ \\
\hline Healthy & 5531 (68.92) & $5044(62.85)$ \\
\hline \multicolumn{3}{|l|}{ Having chronic disease or not, $\mathrm{n}(\%)$} \\
\hline Yes & $1629(20.30)$ & $1637(20.40)$ \\
\hline No & $6396(79.70)$ & $6388(79.60)$ \\
\hline \multicolumn{3}{|l|}{ Health insurance status, $\mathrm{n}(\%)$} \\
\hline Yes & 7304 (91.01) & $7359(91.7)$ \\
\hline No & $721(8.98)$ & $666(8.3)$ \\
\hline \multicolumn{3}{|l|}{ Doing physical exercise or not, $\mathrm{n}(\%)$} \\
\hline Yes & $3861(48.11)$ & $4290(53.46)$ \\
\hline No & $4164(51.89)$ & $3735(46.54)$ \\
\hline \multicolumn{3}{|l|}{ Type of employment, n (\%) } \\
\hline Unemployed & $2771(34.53)$ & $2929(36.50)$ \\
\hline Manager & $423(5.27)$ & $582(7.25)$ \\
\hline Professional and technical staff & 497 (6.19) & $513(6.39)$ \\
\hline Clerks and related personnel & $512(6.38)$ & $429(5.35)$ \\
\hline Service staff & $1194(14.88)$ & $1053(13.12)$ \\
\hline $\begin{array}{l}\text { Production workers in agriculture, } \\
\text { forestry, animal husbandry, fishery } \\
\text { and water conservancy sectors }\end{array}$ & $1212(15.10)$ & $1185(14.77)$ \\
\hline $\begin{array}{l}\text { Operator of production and } \\
\text { transportation equipment and } \\
\text { related personnel }\end{array}$ & 1299 (16.19) & $1124(14.01)$ \\
\hline Other & $117(1.46)$ & $210(2.62)$ \\
\hline \multicolumn{3}{|l|}{ Alcohol intake, n (\%) } \\
\hline Yes & $1305(16.26)$ & $1271(15.84)$ \\
\hline No & $6720(83.74)$ & $6754(84.16)$ \\
\hline
\end{tabular}

Exchange rate of the Chinese Yuan against US\$ were 6.14 and 6.64 in 2014 and 2016 based on China Statistical Yearbook, $2017 .{ }^{36}$ 


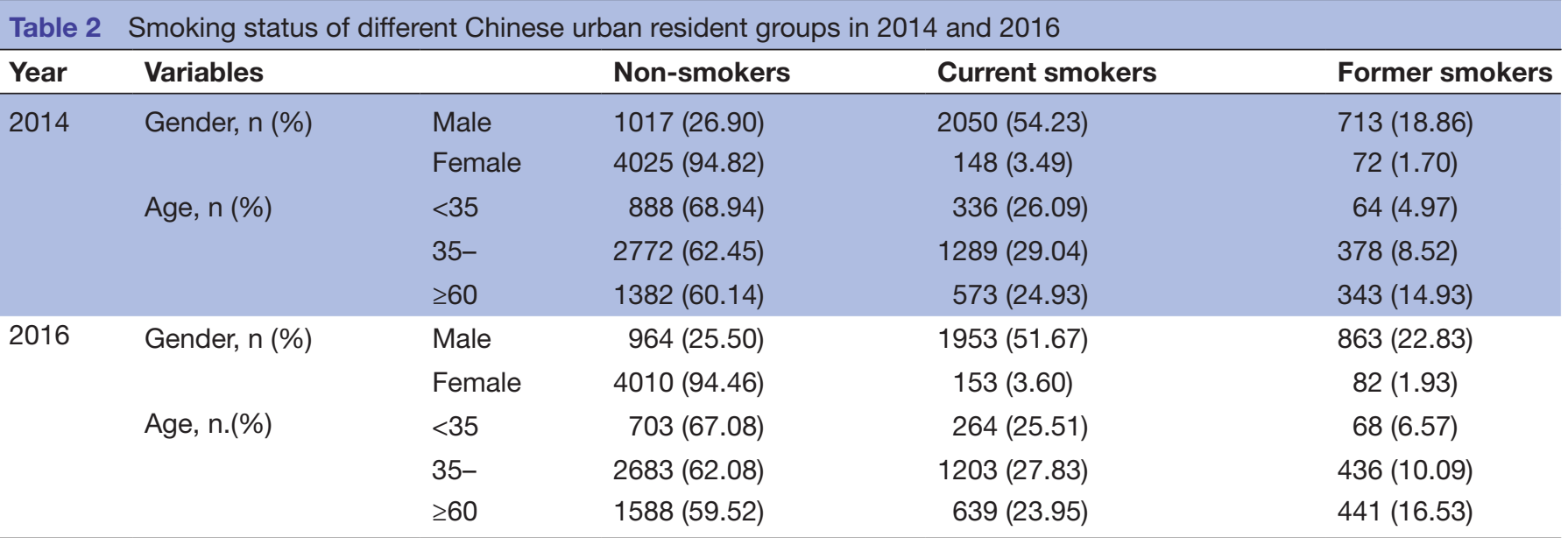

smoking status (see figure 1). It also analyses the effect of smoking on income among Chinese urban residents (see table 3). Finally, it describes the poverty rate in different smoking status (see table 4).

A two-tailed $\mathrm{p}$ value of $<0.05$ was considered statistically significant. All data in this study were analysed with STATA (V.14.0, MP).

\section{RESULTS}

Table 1 reports the sociodemographic characteristics of urban residents in 2014 and 2016. The gender variables were consistent throughout the years: 4245 male samples accounted for $52.90 \%$, while 3779 female samples accounted for $47.10 \%$. The percentage of current smokers dropped from $27.39 \%$ in 2014 to $26.24 \%$ at the end of 2016, and the percentage of former smokers increased from $9.78 \%$ to $11.78 \%$. The annual income of the urban residents showed an overall upward trend,

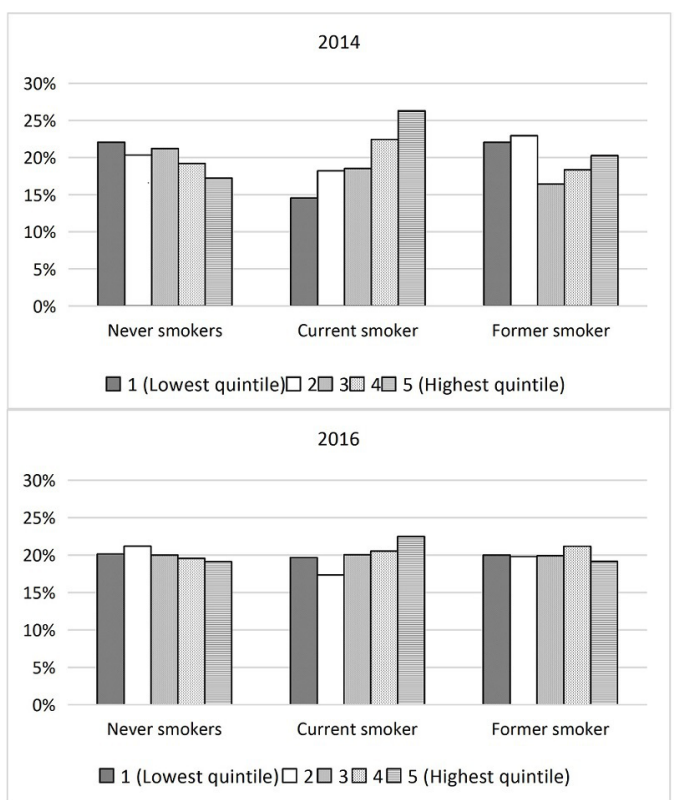

Figure 1 Income distribution of urban resident in different smoking status in 2014 and 2016, China. increasing from US $\$ 2761.93$ in 2014 to US $\$ 4807.02$ in 2016. The education level of the urban residents was generally not high, and more than half of the subjects were graduates from middle school or high school. The prevalence of chronic disease in both 2014 and 2016 was approximately $20 \%$. More than $60 \%$ of the respondents rated their health status as healthy.

Table 2 analyses the smoking status of Chinese urban residents with different characteristics. In 2014 and 2016, the current smoking prevalence for men was $54.23 \%$ and $51.67 \%$, and the current smoking prevalence for women was $3.49 \%$ and $3.60 \%$, respectively. In both years, the current smoking prevalence of the 35- age group was the highest, accounting for $29.04 \%$ and $27.83 \%$, respectively, and group aged 60 and above has the highest former smoking prevalence, which was $14.93 \%$ and $16.53 \%$, respectively.

Figure 1 shows the distribution of income levels for the different smoking status categories in 2014 and 2016. All urban residents were divided into five groups based on their annual income levels. The levels ranged from 1 to 5 and represented the population groups from the lowest $20 \%$ income group to the top $20 \%$ income group, respectively. Our studies have shown that the percentage of highincome non-smokers rose from $17.22 \%$ in 2014 to $19.12 \%$ in 2016, while the percentage of low-income non-smokers decreased from $22.05 \%$ to $20.14 \%$. The percentage of high-income current smokers decreased from $26.30 \%$ in 2014 to $22.46 \%$ in 2016 , while the percentage of lowincome current smokers rose from $14.56 \%$ to $19.66 \%$. The percentage of high-income former smokers decreased from $20.25 \%$ in 2014 to $19.15 \%$ in 2016 , and the percentage of low-income former smokers decreased from $22.04 \%$ to $20.00 \%$.

Table 3 presents the effects of smoking on the income of urban residents. Model 1 is an analysis of the income impact among all respondents. Models 2-4 analyse the effects of smoking on the income level of different age groups, namely, young people $(<35$ years), middle-aged people (35-59 years old) and elderly people ( $\geq 60$ years old). As is shown in model 1, smoking has a significant 
Table 3 Analysis of the effect of smoking on income among Chinese urban residents

\begin{tabular}{|c|c|c|c|c|}
\hline Variables & $\begin{array}{l}\text { Model } 1 \\
\text { (total population) }\end{array}$ & $\begin{array}{l}\text { Model } 2 \\
\text { (young people) }\end{array}$ & $\begin{array}{l}\text { Model } 3 \\
\text { (middle-aged people) }\end{array}$ & $\begin{array}{l}\text { Model } 4 \\
\text { (elderly people) }\end{array}$ \\
\hline \multicolumn{5}{|l|}{ Smoking status (reference group: non-smokers) } \\
\hline Current smokers & $-0.377^{\star \star}$ & -0.129 & $-0.550^{\star \star \star}$ & -0.0991 \\
\hline \multirow[t]{2}{*}{ Former smokers } & $-0.440^{\star *}$ & -0.107 & $-0.624^{\star \star \star}$ & -0.300 \\
\hline & $(-2.34)$ & $(-0.48)$ & $(-2.95)$ & $(-0.66)$ \\
\hline \multirow[t]{2}{*}{ Gender (reference group: female) } & $0.455^{\star \star \star}$ & $0.335^{* *}$ & $0.595^{\star \star \star}$ & 0.285 \\
\hline & (3.68) & $(2.48)$ & $(4.01)$ & $(0.97)$ \\
\hline \multicolumn{5}{|l|}{ Age (reference group: $<35$ years) } \\
\hline $35-$ & $-0.0643^{*}$ & - & - & - \\
\hline \multirow[t]{2}{*}{ Marital status (reference group: not in marriage) } & $0.0557^{*}$ & 0.0675 & $0.149^{\star \star \star}$ & 0.0286 \\
\hline & $(1.71)$ & $(1.35)$ & $(3.02)$ & $(0.45)$ \\
\hline \multicolumn{5}{|l|}{ Education (reference group: primary school and below) } \\
\hline \multirow[t]{2}{*}{ Middle school and high school } & $0.295^{\star \star \star}$ & $0.283^{\star \star \star}$ & $0.159^{\star \star \star}$ & $0.482^{\star \star \star}$ \\
\hline & $(11.02)$ & $(3.85)$ & $(5.18)$ & $(8.96)$ \\
\hline \multirow[t]{2}{*}{ Junior college and above } & $0.772^{\star \star \star}$ & $0.656^{\star \star \star}$ & $0.766^{\star \star \star}$ & $0.946^{\star \star \star}$ \\
\hline & $(16.74)$ & (7.52) & $(14.47)$ & $(7.66)$ \\
\hline \multicolumn{5}{|l|}{ Self-rated health (reference group: poor) } \\
\hline \multirow[t]{2}{*}{ Average } & $0.130^{\star \star \star}$ & -0.00716 & $0.0735^{\star}$ & $0.143^{\star \star}$ \\
\hline & $(3.69)$ & $(-0.07)$ & $(1.81)$ & (2.32) \\
\hline \multirow[t]{2}{*}{ Doing physical exercise or not (reference group: no) } & $0.0578^{\star \star \star}$ & 0.0517 & 0.0358 & $0.163^{* \star *}$ \\
\hline & $(2.82)$ & $(1.41)$ & $(1.57)$ & $(3.77)$ \\
\hline \multicolumn{5}{|l|}{ Type of employment (reference group: unemployed) } \\
\hline \multirow[t]{2}{*}{ Manager } & $0.338^{\star \star \star}$ & $0.613^{\star \star \star}$ & $0.393^{\star \star *}$ & 0.190 \\
\hline & $(7.37)$ & $(7.50)$ & $(8.38)$ & $(1.23)$ \\
\hline \multirow[t]{2}{*}{ Professional and technical staff } & $0.570^{\star \star \star}$ & $0.680^{\star * \star}$ & $0.619^{\star \star \star}$ & $0.820^{\star \star *}$ \\
\hline & (11.19) & (9.38) & (10.65) & (3.52) \\
\hline \multirow[t]{2}{*}{ Clerks and related staff } & $0.557^{\star \star \star}$ & $0.610^{\star \star \star}$ & $0.602^{\star \star *}$ & $0.696^{\star \star \star}$ \\
\hline & $(11.48)$ & $(8.14)$ & $(11.26)$ & $(4.41)$ \\
\hline Service staff & $0.333^{* \star *}$ & $0.516^{\star \star \star}$ & $0.351^{\star \star \star}$ & $0.344^{* \star *}$ \\
\hline & $(9.59)$ & $(8.39)$ & $(9.58)$ & $(3.10)$ \\
\hline Production workers in agriculture, forestry, animal husbandry, & $-0.382^{\star \star \star}$ & -0.153 & $-0.170^{\star \star \star}$ & $-0.649^{\star \star \star}$ \\
\hline fishing and water conservancy sectors & $(-11.28)$ & $(-1.60)$ & $(-4.27)$ & $(-10.87)$ \\
\hline Operators of production and transportation equipment and & $0.576^{\star \star \star}$ & $0.594^{\star \star \star}$ & $0.585^{\star \star *}$ & $0.873^{\star \star *}$ \\
\hline & (15.83) & (9.03) & (15.34) & (6.52) \\
\hline Other & $0.144^{\star *}$ & $0.346^{\star \star \star}$ & $0.264^{\star * \star}$ & -0.265 \\
\hline & $(2.06)$ & $(2.90)$ & (3.78) & $(-1.25)$ \\
\hline Ln GDP per capita & $0.543^{\star \star \star}$ & $0.652^{\star \star \star}$ & $0.482^{\star \star \star}$ & $0.630^{\star \star \star}$ \\
\hline & (19.84) & $(11.41)$ & $(14.76)$ & (11.74) \\
\hline
\end{tabular}




\begin{tabular}{|c|c|c|c|c|}
\hline Variables & $\begin{array}{l}\text { Model } 1 \\
\text { (total population) }\end{array}$ & $\begin{array}{l}\text { Model } 2 \\
\text { (young people) }\end{array}$ & $\begin{array}{l}\text { Model } 3 \\
\text { (middle-aged people) }\end{array}$ & $\begin{array}{l}\text { Model } 4 \\
\text { (elderly people) }\end{array}$ \\
\hline \multirow[t]{2}{*}{2016} & $1.036^{\star \star \star}$ & $0.314^{\star \star \star}$ & $0.472^{\star \star \star}$ & $2.399^{\star \star \star}$ \\
\hline & (59.74) & (10.91) & (25.58) & $(65.86)$ \\
\hline Constant & $2.516^{\star \star \star}$ & $1.587^{\star \star}$ & $3.365^{\star \star \star}$ & 0.132 \\
\hline $\mathrm{N}$ & 16050 & 2576 & 8878 & 4596 \\
\hline
\end{tabular}

t-Statistics in parentheses.

${ }^{*} \mathrm{P}<0.1,{ }^{* *} \mathrm{p}<0.05,{ }^{* * *} \mathrm{p}<0.01$

GDP, gross domestic product.

negative impact on income $(\mathrm{p}<0.05)$. Compared with the annual income of non-smokers, current smokers and former smokers are associated with statistically significant decrease in the income of urban residents of $37.70 \%$ and $44.00 \%$, respectively.With improvements in education, the annual income of urban residents also increased. The income of residents with good self-rated health was significantly higher than that of urban residents with poor self-rated health. Smoking did not significantly affect the annual income of the young and elderly urban residents (see models 2 and 4), but it significantly reduced the income of middle-aged urban residents. In comparison with the annual income of non-smokers, current smokers and former smokers are associated with statistically

\begin{tabular}{|c|c|c|c|c|c|}
\hline Category & $\begin{array}{l}\text { Income } \\
\text { level }\end{array}$ & $\begin{array}{l}\text { Non- } \\
\text { smokers }\end{array}$ & $\begin{array}{l}\text { Current } \\
\text { smokers }\end{array}$ & $\begin{array}{l}\text { Former } \\
\text { smokers }\end{array}$ & Total \\
\hline \multirow{6}{*}{$\begin{array}{l}\text { Impact of } \\
\text { smoking } \\
\text { on income } \\
\text { retained }\end{array}$} & $\begin{array}{l}\text { Q1 } \\
\text { (lowest 20\% } \\
\text { income) }\end{array}$ & 61.35 & 54.90 & 58.84 & 59.60 \\
\hline & Q2 & 16.54 & 18.24 & 17.39 & 17.04 \\
\hline & Q3 & 0.00 & 0.00 & 0.00 & 0.00 \\
\hline & Q4 & 0.00 & 0.00 & 0.00 & 0.00 \\
\hline & $\begin{array}{l}\text { Q5 } \\
\text { (top 20\% } \\
\text { income) }\end{array}$ & 0.00 & 0.00 & 0.00 & 0.00 \\
\hline & Subtotal & 16.38 & 12.59 & 16.01 & 15.33 \\
\hline \multirow{6}{*}{$\begin{array}{l}\text { Impact of } \\
\text { smoking } \\
\text { on income } \\
\text { eliminated }\end{array}$} & $\begin{array}{l}\text { Q1 } \\
\text { (lowest 20\% } \\
\text { income) }\end{array}$ & 61.35 & 48.30 & 53.04 & 57.41 \\
\hline & Q2 & 16.54 & 0.00 & 0.00 & 10.75 \\
\hline & Q3 & 0.00 & 0.00 & 0.00 & 0.00 \\
\hline & Q4 & 0.00 & 0.00 & 0.00 & 0.00 \\
\hline & $\begin{array}{l}\text { Q5 } \\
\text { (top 20\% } \\
\text { income) }\end{array}$ & 0.00 & 0.00 & 0.00 & 0.00 \\
\hline & Subtotal & 16.38 & 8.25 & 11.10 & 13.63 \\
\hline
\end{tabular}

The poverty line criterion used was the 2010 poverty line standard of 2300 yuan per year. The nominal value was corrected with the consumer price index and transformed based on the poverty line measured by the constant price of 2014 . significant decrease in the income of urban residents (see Model 3).

As shown in table 4 , the average poverty rate among Chinese urban residents in 2014 and 2016 was $15.33 \%$, among which the poverty rate among former smokers, current smokers and non-smokers were $16.01 \%, 12.59 \%$ and $16.38 \%$, respectively. The lowest income group had the highest poverty rate among all income groups. After eliminating the impact of smoking on income, which means raising the annual income of current smokers and former smokers by $37.70 \%$ and $44.00 \%$, respectively, the poverty rate among urban residents was reduced to $13.63 \%$, and the poverty rate among former smokers and current smokers was reduced to $10.10 \%$ and $8.25 \%$, respectively.

\section{DISCUSSION}

This study revealed that smoking has a significant negative impact on the income of urban residents in China. The current annual income of current smokers was $37.70 \%$ less than that of non-smokers, while the income of former smokers was $44.00 \%$ less than that of non-smokers. After eliminating the impact of smoking on income, the poverty rate among urban residents was reduced by more than $1 \%$, which means a population of approximately 13.11 million was no longer in poverty.

This study revealed a higher impact of smoking on income than in previous studies. ${ }^{9-11}$ Possible reasons are as follows. First, Chinese smokers consume an average of 15.2 cigarettes per day, ${ }^{21}$ which reaches a heavy smoking level. ${ }^{22}$ The greater the amount of smoking, the more serious health impacts there will be, which will result in a greater impact on personal income. ${ }^{23-25}$ Second, in previous studies, smoking status was categorised into two groups, namely, smoking and non-smoking, which mistakenly categorised former smokers as non-smokers and thus underestimated the impact of smoking on income.

Smoking had different impacts on the personal income of people in different age groups. Smoking significantly reduced the income of middle-aged urban residents but did not significantly affect the income of young and elderly residents. The possible reasons are as follows. First, the harms of smoking have a cumulative and 
delayed effect, and the impacts of smoking on health are not yet evident in one's youth. ${ }^{26}$ After smokers become middle-aged, smoking gradually shows its negative impact on health. ${ }^{27}$ Second, the current legal retirement age for Chinese workers is 60 for men and 50-55 for women. ${ }^{28}$ Most people in age groups above 60 years have retired with relatively stable retirement pensions. Therefore, there is little relationship between their income and health status. Moreover, the relationship between health status and work hours as well as work ability is also minimally related to income.

From a policy perspective, reduction of smoking prevalence is not only a matter of public health concern but also closely related to the reduction of poverty. As the most populated middle-income country in the world, China has always aimed to reduce and eradicate poverty as a long-term task in the process of economic development. ${ }^{29}$ To control the harm of tobacco, it is first recommended to make the most of the battle against poverty by integrating tobacco control strategies with national poverty alleviation policies. This effort will help overcome various economic and political obstacles in the implementation of existing tobacco control measures and facilitate the Chinese government's efforts to build a comprehensive, healthy society. Second, it is recommended to gradually increase the tax rate on tobacco and thereby increase cigarette retail prices to curb the tobacco epidemic. Raising tobacco taxes is the most cost-effective way to reduce tobacco use. ${ }^{30}$ In addition, low-income groups are more sensitive to price changes; therefore, it is easier to reduce the demand for cigarettes among these groups. ${ }^{31}$ Consequently, the low-income groups will receive most of the health and economic benefits of tax increases, ${ }^{32}$ which is conducive to reducing the financial risks of low-income groups and the poverty rate. Third, it is recommended to cover smoking cessation treatment in medical insurance to alleviate the financial burden on smokers. Research has shown that patients with medical insurance are more willing to quit smoking than patients without medical insurance and that expanding health insurance coverage can improve the smoking cessation rate. ${ }^{33}$ Fourth, it is recommended to promote publicity campaigns about tobacco harm and to encourage smokers to quit smoking as early as possible. The low awareness of Chinese residents about the harm of tobacco is to some degree related to the tobacco industry's use of 'low tar' marketing strategies; therefore, it is recommended to stop implementing this deceptive tobacco marketing strategy. ${ }^{6}$ Furthermore, the effect of warnings on tobacco packaging are not adequate. Studies have shown that the combination of text and pictures is more alarming than just a text warning. ${ }^{34}$ It is therefore recommended to promote the use of warning pictures instead of the traditional text warnings on cigarette packages.

The major contributions of this article lie in the following three aspects. First, we have supplemented the empirical research conclusions on the relationship between smoking and resident income in China. Moreover, two-wave balance panel data can provide more data points, increase the degree of data freedom, reduce the degree of colinearity between explanatory variables and thus improve the effectiveness of model estimation. It can also control individual heterogeneity, which helps improve the estimation accuracy. ${ }^{35}$ Finally, the Hausman-Taylor model successfully addresses the problems of inconsistencies in the random effects model and the ineffectiveness of the fixed effects model by avoiding the disadvantages of the pooled regression model, which fails to consider the influence of individual differences. In addition, the Hausman-Taylor model can also overcome the endogeneity problems with the instrumental variables automatically generated from internal information in the model. ${ }^{19}$

Nevertheless, this study has some limitations. First, CHARLS is a retrospective self-reported survey, and recall bias may be inevitable. Second, the study was limited to urban residents without consideration of the impact of smoking on the income of other populations.

\section{Author affiliations}

${ }^{1}$ School of Management, Chengdu University of Traditional Chinese Medicine, Chengdu, Sichuan, China

${ }^{2}$ School of Public Health, Chengdu University of Traditional Chinese Medicine, Chengdu, Sichuan, China

${ }^{3}$ Institute for Health \& Aging, University of California, San Francisco, San Francisco, California, USA

${ }^{4}$ Huaxi School of Public Health, Sichuan University, Chengdu, Sichuan, China

Acknowledgements The authors are grateful to Professor Teh-Wei Hu, Professor Anita H Lee, Professor Shuang Ma and PhD Jiancheng Wang, for their advice and support during the process of data analysis.

Contributors Conceptualisation: LY; formal analysis: ZM; methodology: HW, ZZ and $\mathrm{SH}$; writing —original draft: HW and ZZ; writing — review and editing: LY, HW, ZM and TY.

Funding This study was supported by the National Natural Science Foundation of China, grant number 71603032.

Patient and public involvement Patients and/or the public were not involved in the design, or conduct, or reporting, or dissemination plans of this research.

Patient consent for publication Not required.

Ethics approval Research ethical or governance approval is exempt for this study as no new data are being collected.

Provenance and peer review Not commissioned; externally peer reviewed.

Data availability statement Data are available in a public, open access repository. The personal level data of Chinese urban residents in our study are all from China Family Panel Studies (CFPS). The data users of CFPS are all over the world. Interested researchers may contact and apply for data via the following contact information: Email:isss.cfps@pku.edu.cn. URL: http://charls.pku.edu.cn/. Interested researchers can request data by clicking open the URL and follow instructions.

Open access This is an open access article distributed in accordance with the Creative Commons Attribution Non Commercial (CC BY-NC 4.0) license, which permits others to distribute, remix, adapt, build upon this work non-commercially, and license their derivative works on different terms, provided the original work is properly cited, appropriate credit is given, any changes made indicated, and the use is non-commercial. See: http://creativecommons.org/licenses/by-nc/4.0/.

ORCID iD

Han Wei http://orcid.org/0000-0003-1996-2798

\section{REFERENCES}

1 Chinese Center of Disease Control and Prevention. Global adults tobacco survey (GATS) China 2018 country report, 2019. Available: https://www.tobaccofreekids.org/assets/global/pdfs/en/GATS_ China_2018_FactSheet.pdf 
2 Zhou M, Wang H, Zeng X, et al. Mortality, morbidity, and risk factors in China and its provinces, 1990-2017: a systematic analysis for the global burden of disease study 2017. Lancet 2019;394:1145-58.

3 Lin $\mathrm{H}-\mathrm{H}$, Murray M, Cohen T, et al. Effects of smoking and solid-fuel use on COPD, lung cancer, and tuberculosis in China: a time-based, multiple risk factor, modelling study. Lancet 2008;372:1473-83.

4 Huxley RR, Woodward M. Cigarette smoking as a risk factor for coronary heart disease in women compared with men: a systematic review and meta-analysis of prospective cohort studies. Lancet 2011;378:1297-305.

5 Brinton LA, Schairer C, Haenszel W, et al. Cigarette smoking and invasive cervical cancer. JAMA 1986;255:3265-9.

6 Yang G. Marketing 'less harmful, low-tar' cigarettes is a key strategy of the industry to counter tobacco control in China. Tob Control 2014;23:167-72.

7 Yang G, Wang Y, Wu Y, et al. The road to effective tobacco control in China. Lancet 2015;385:1019-28.

8 Böckerman P, Hyytinen A, Kaprio J. Smoking and long-term labour market outcomes. Tob Control 2015;24:348-53.

9 Auld MC. Smoking, drinking, and income. J Hum Resour 2005;XL:505-18.

10 van Ours JC. A pint a day raises a man's pay; but smoking blows that gain away. J Health Econ 2004;23:863-86.

11 Lokshin M, Beegle K. Forgone earnings from smoking: evidence for a developing country. Washington DC: The World Bank, 2006.

12 Lye * JN, Hirschberg J. Alcohol consumption, smoking and wages. Appl Econ 2004;36:1807-17.

13 Kristein MM. How much can business expect to profit from smoking cessation? Prev Med 1983;12:358-81.

14 Becker GS, Murphy KM. A theory of rational addiction. J Polit Econ 1988;96:675-700.

15 Frieze IH, Olson JE, Russell J. Attractiveness and income for men and women in management. J Appl Soc Psychol 1991;21:1039-57.

16 Yin ZC, Gan L. Cigarettes, wine and income. Econ Res2010;10:90-100.

17 Institute of Social Science Survey, PU. China family panel studies (CFPS), Peking university open research data platform. Available: http://www.isss.pku.edu.cn/cfps/

18 Zhang XB. The effect of smoking and drinking on the income of Chinese urban residents and their spouses. Southwestern University of finance and economics, 2014.

19 Hausman JA, Taylor WE. Panel data and unobservable individual effects. Econometrica 1981;49:1377-98.

20 Mincer J. Schooling, experience, and earnings. New York: Columbia University Press, 1974.
21 Chinese Center for Disease Control and Prevention. Chinese adult tobacco survey report, 2015. Available: http://www.tcrc.org.cn/ UploadFiles/2016-03/318/201603231215175500.pdf

22 Stevens DP, Mackay IR. Increased carcinoembryonic antigen in heavy cigarette smokers. Lancet 1973;2:1238-9.

23 Bjartveit K, Tverdal A. Health consequences of smoking 1-4 cigarettes per day. Tob Control 2005:14:315-20.

24 Launoy G, Milan CH, Faivre J, et al. Alcohol, tobacco and oesophageal cancer: effects of the duration of consumption, mean intake and current and former consumption. Br J Cancer 1997;75:1389-96.

$25 \mathrm{Ng} \mathrm{M}$, Freeman MK, Fleming TD, et al. Smoking prevalence and cigarette consumption in 187 countries, 1980-2012. JAMA 2014;311:183-92.

26 US Department of Health and Human Services. Reducing the health consequences of smoking. 25 years of progress. Smoking and Health 1989:43-54.

27 Liu Y, Rao K, Hu T-W, et al. Cigarette smoking and poverty in China. Soc Sci Med 2006;63:2784-90.

28 State Council Circular on Issuing. "State council temporary measures on providing for old, weak, sick, and handicapped cadres" and "State Council Temporary Measures on Workers" Retirement, Resignation. Available: http://www.npc.gov.cn/wxzl/wxzl/2000-12/ 07/content_9552.htm [Accessed 28 Dec 2019].

29 Wei Z. The status quo and causes of China's capability PovertyAn analysis based on multidimensional dynamic measure study. People's Tribune. Frontiers 2012;5:10.

$30 \mathrm{Hu}$ T-W, Mao Z, Shi J, et al. The role of taxation in tobacco control and its potential economic impact in China. Tob Control 2010;19:58-64.

31 Choi SE. Are lower income smokers more price sensitive?: the evidence from Korean cigarette tax increases. Tob Control 2016;25:141-6.

32 Jha P, Joseph R, Li D. Tobacco taxes: a win-win measure for fiscal space and health. Asian Development Bank, 2012.

33 Yip D, Gubner N, Le T, et al. Association of medicaid expansion and health insurance with receipt of smoking cessation services and smoking behaviors in substance use disorder treatment. J Behav Health Serv Res 2020;47:264-74.

34 Woelbert E, d'Hombres B. Pictorial health warnings and wear-out effects: evidence from a web experiment in 10 European countries. Tob Control 2019;28:e71-6.

35 Xiao Z. Panel data analysis. Beijing: Peking University press, 2005.

36 National Bureau of statistics of China. China's statistical Yearbook 2017. Beijing: China Statistics, 2017. 